\title{
INVESTIGATION OF INFLUENCE OF CALIBRATION OF GRAIN MOTH EGGS ON PRODUCTION OF TRICHOGRAMMA FOR BIOLOGICAL PROTECTION OF PLANTS
}

\author{
Oleh Marus, Gennadii Golub, Viacheslav Chuba \\ National University of Life and Environmental Sciences of Ukraine, Ukraine \\ marus_o@ukr.net,gagolub@ukr.net,vvchuba@ukr.net
}

\begin{abstract}
Improving the production of the biological preparation Trichogramma is an urgent task, as the quality indicators of the preparation Trichogramma determine its ability to provide effective biological protection of plants. The influence of the process of calibration of grain moth eggs on the production of Trichogramma was determined. This made it possible to recommend the developed grain moth eggs calibrator for use in the Trichogramma preparation process. With using of selected large grain moth eggs, Trichogramma evanescens Westw. was reproduced for six generations. The grain moth eggs, which were only cleaned, were used as controls. Also studies are conducted of the reproduction of Trichogramma pintoi Voeg., using selected large grain moth eggs for seven generations. The small grain moth eggs, which were obtained during pneumatic calibration, were used as controls. By the relationship between the grain moth eggs size and the Trichogramma pintoi Voeg. and Trichogramma evanescens Westw., the level of parasitized eggs was established. Studies have shown that Trichogramma pintoi Voeg. with using of selected large grain moth eggs from the third to the seventh generation had a level of parasitized eggs, which ranged from 76 to $90 \%$. When the small grain moth eggs were used, the level of parasitized eggs sharply decreased from the third to the ninth generation. Trichogramma evanescens Westw., which bred on large grain moth eggs from the second to the seventh generation, had parasitized eggs, ranging from 83 to 93\%. When cultivating Trichogramma evanescens Westw. on grain moth eggs that have been cleaned only without calibration, the high level of parasitized eggs in the range of 78 to $80 \%$ was only from the second to fourth generation. Since the fifth generation, Trichogramma evanescens Westw. level of parasitized eggs of the grain moth have been reduced and it led to a decreasing efficiency of the biological preparation Trichogramma.
\end{abstract}

Keywords: pneumatic calibration, grain moth eggs, preparation Trichogramma, level of parasitized eggs.

\section{Introduction}

The using of chemical drugs against pests of agricultural crops leads to negative consequences for the environment, and, thus, for humans. The use of chemical drugs leads to a decrease in the soil fertility and crop yields [1]. Biological plant protection allows obtaining environmentally safe products and improving the ecological situation. Providing of environmental safety leads to the development and introduction of organic production technologies. In recent times, there has been a tendency to increase the number of such enterprises [2].

In biological protection of plants from lepidopterous pests the most common is Trichogramma. In Ukraine, Trichogramma is used on vegetable, technical, grain, leguminous crops and fruit plantations against owlet moths, white butterflies, pyralid moths, leaf rollers, moths and other pests.

A significant amount of scientific papers is related to the effectiveness of the use of Trichogramma against agricultural pests [3; 4], as well as to the study the influence of the action of chemical plant protection products on the viability of the entomological agent [5; 6]. Known research results [7] on determination of the effect of Mamestra brassicae L. egg size on fertility and sex distribution Trichogramma evanescens Westw. These studies determined how Mamestra brassicae L. eggs are parasitized, when several wasps of Trichogramma were released per egg of the pest. It was found that at the beginning of egg-laying by Trichogramma females more males are hatched from eggs.

The studies of infection of grain moth eggs at different ratios of Trichogramma females to the number of grain moth eggs were made by Pallewatta [8]. The studies determined the average number of males and females in progeny, the average number of eggs laid and the average tibia length of the Trichogramma progeny. The author notes that the studies were conducted using grain moth eggs of approximately the same size in one generation of Trichogramma.

The process of Trichogramma producing consists of two stages. In the first stage of Trichogramma producing most production laboratories use the grain pest - grain moth (Sitotroga cerealella). The second one is related to Trichogramma production, which is cultivated on the eggs of grain moth obtained at the first stage of the production. 
The scheme of Trichogramma production shown in Figure 1 involves calibration of eggs of grain moth after cleaning them. This operation allows separating the eggs of grain moth into fractions, and in the future using only large eggs for breeding Trichogramma.

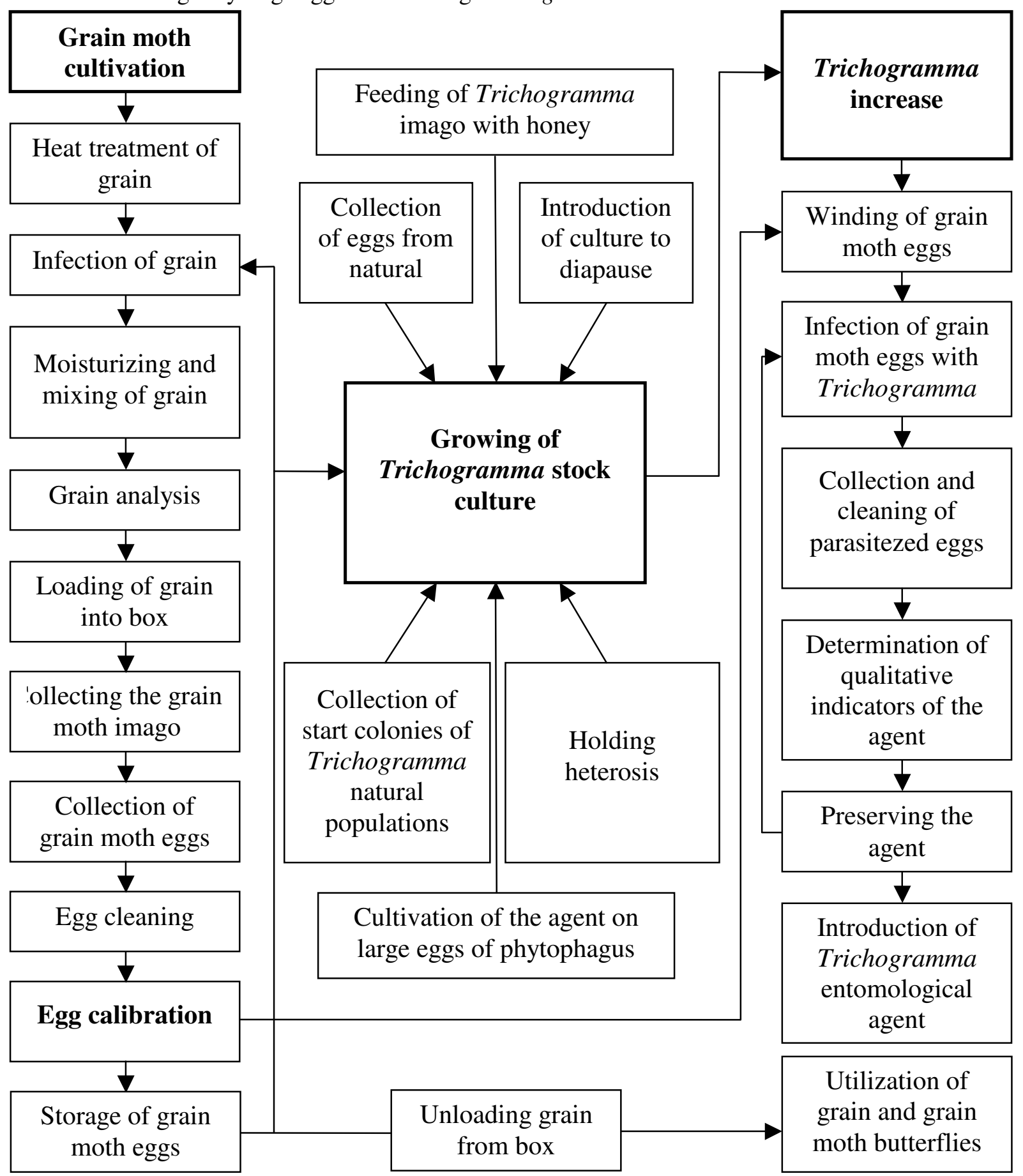

Fig. 1. Scheme of technological process of Trichogramma production

Investigation of the impact of the process of calibration of grain moth eggs on the production of Trichogramma for biological protection of plants will allow establishing the importance of this operation. Improving the quality of Trichogramma will affect the effectiveness of its application in plant biological protection.

\section{Materials and methods}

In order to establish the characteristic sizes of eggs of grain moth, the work was done at the Plant Protection Department of the All-Union Research Institute of Biological Methods of Plant Protection 
[9]. These studies have made it possible to establish a minimum volume of large eggs of grain moth for the production of Trichogramma stock culture, which was $0.0247 \mathrm{~mm}^{3}$ (for grain moth cultivation regime with weak violations).

The elongated ellipsoid formula was used to calculate the volume of grain moth eggs:

$$
V=\frac{\pi L B^{2}}{6}, \mathrm{~mm}^{3}
$$

where $\quad V$ - volume of grain moth egg, $\mathrm{mm}^{3}$;

$L, B$ - length and the width of grain moth egg, $\mathrm{mm}$.

Pneumatic calibrator of grain moth eggs (Fig. 2) was used to separate the eggs of grain moths. Using it, the eggs of grain moth were divided into three fractions: conglomerates (stuck eggs of grain moth), which fell into the first container; large eggs - fell into the second container; small eggs - fell into the third container. Pneumatic grain moth calibrator after improvement [10] provided a probability of selection of large grain moth eggs at the level of $58 \%$.

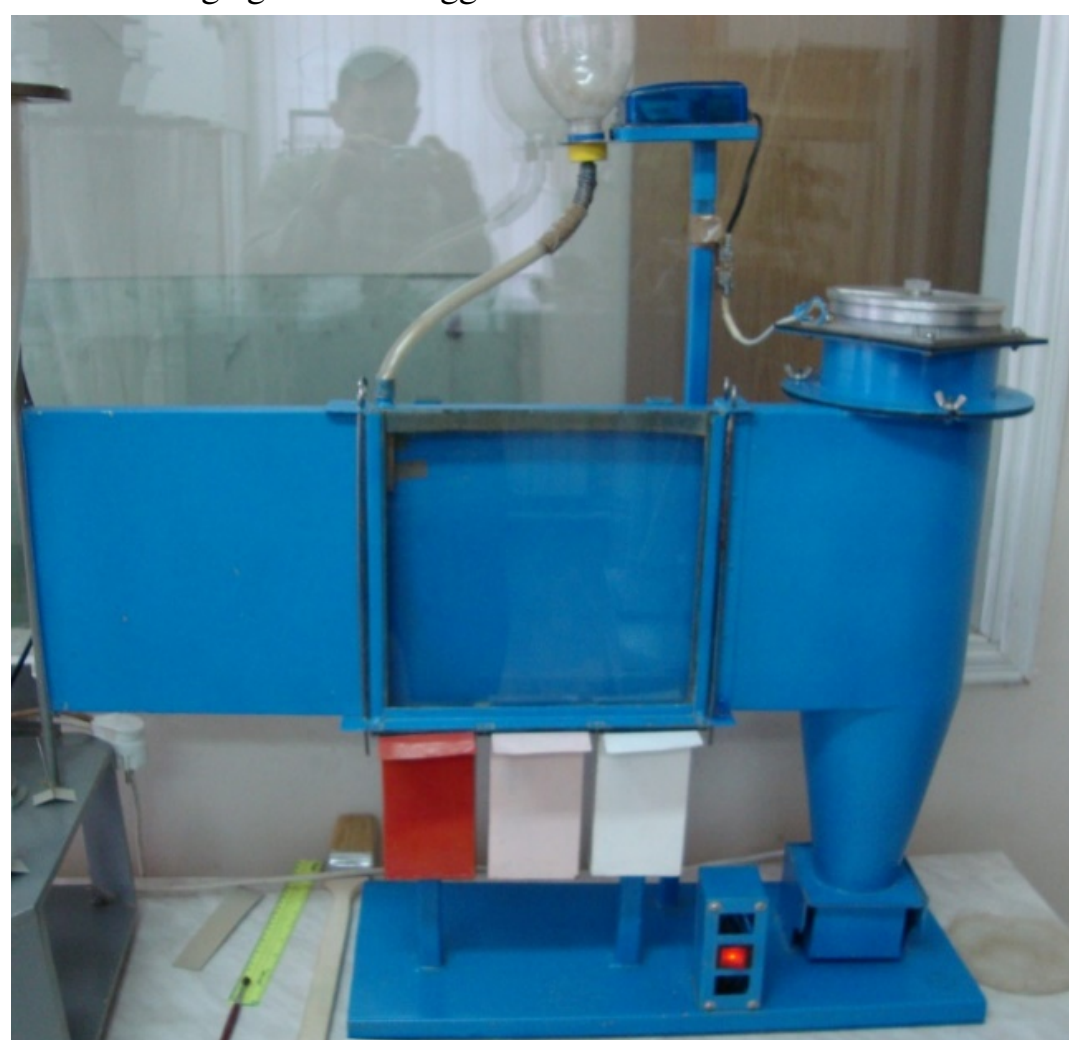

Fig. 2. General view of the pneumatic calibrator of grain moth eggs

With the selected large eggs of grain moth Trichogramma evanescens Westw. reproduction was carried out. As controls, the eggs that were only cleaned were used. These studies were performed with Trichogramma evanescens Westw. from the second to sixth generation.

At the beginning, the level of parasitized eggs Trichogramma evanescens Westw. was determined in the first generation using the eggs that had only been cleaned. In the first generation, the level of the parasitized eggs by Trichogramma evanescens Westw. was 82\%. Starting from the second generation, breeding Trichogramma evanescens Westw. was carried out on large eggs of grain moth obtained after cleaning and calibration and on grain moth eggs after clearing without calibration. All studies were conducted in three replicates.

Also, for the purpose of comparing and determining the importance of the operation of calibration of the grain moth eggs, studies were conducted on the reproduction of Trichogramma pintoi Voeg. on the selected large eggs of grain moth. The small grain moth eggs, which were obtained during pneumatic calibration, were used as controls. The studies were conducted over seven generations 
(from 3 to 9 generations). In the second generation, the level of the parasitized eggs by Trichogramma pintoi Voeg. was $84 \%$.

The level of the parasitized eggs by Trichogramma was determined by known methods [11]. The level of parasitized eggs as the ratio of the number of parasitized eggs to the total number of eggs of grain moth in a limited volume was determined using a stereoscopic microscope MBS-10 type AC 3.850.005 RE and a device for determining the infection of eggs by Trichogramma, which consists of 10 separate sectors, on which the parasitized eggs was evenly spread out. In each sector, the total number of eggs and parasitized eggs of grain moth was counted.

The results of studies on determining the effect of the eggs size of grain moth on the level of the parasitized eggs by Trichogramma were statistically processed using a well-known Fisher criterion (Fcriterion) that compares variances of the two variation series.

\section{Results and discussion}

Researches on the effect of the size of grain moth eggs on the level of the parasitized eggs by Trichogramma evanescens Westw. showed (Fig. 3) that from the second to seventh generation of Trichogramma, which was cultivated on large eggs of grain moth, provides an average of $20.4 \%$ more the level of parasitized eggs than the fraction prior to the calibration (which was only cleaned). The value of Fisher's criterion for the two variation series was $F=5.3$, which is more than the tabular value of 2.3. This indicates the significance of the deviations of the values of the obtained level of parasitized eggs for large eggs of grain moth compared with the level of parasitized eggs for eggs of grain moth which passed only cleaning without calibration.

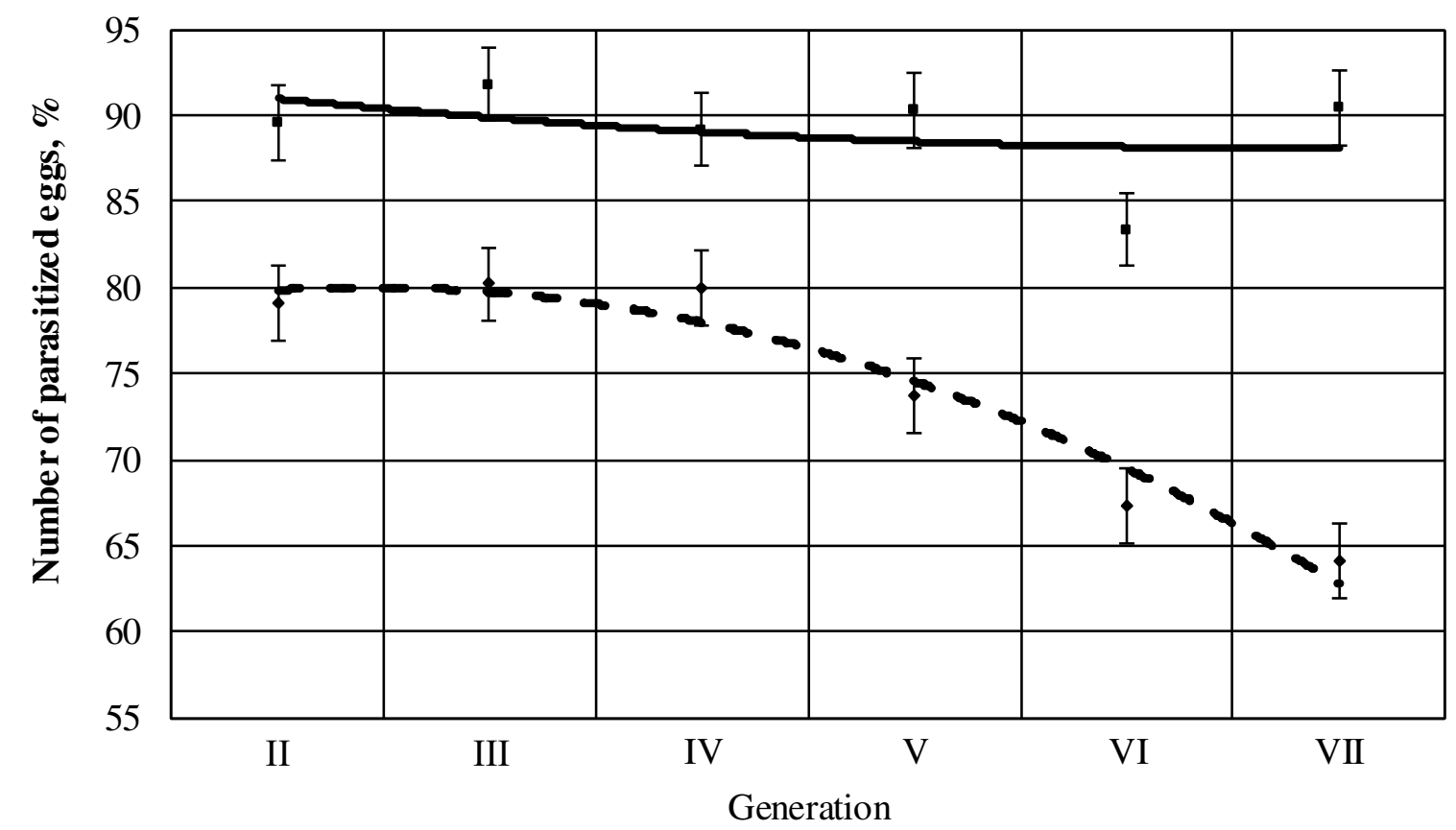

- Eggs prior to the calibration - Large eggs

Fig. 3. Influence of the size of grain moth eggs on the level of parasitized eggs by Trichogramma evanescens Westw.

We also studied the influence of large and small eggs of grain moth on the level of parasitized eggs of Trichogramma pintoi Voeg. Determination of the effect of the size of grain moth eggs on the level of parasitized eggs by Trichogramma pintoi Voeg. (Fig. 4) showed that while cultivating on small eggs of grain moth obtained from the third container of a pneumatic calibrator, the level of parasitized eggs is sharply reducing from the third to ninth generation. At the same time, while cultivating Trichogramma pintoi Voeg. on large eggs of grain moth selected from the second container of a pneumatic calibrator, the level of parasitized eggs was in the range of 76 to $90 \%$ from the third to seventh generation. 


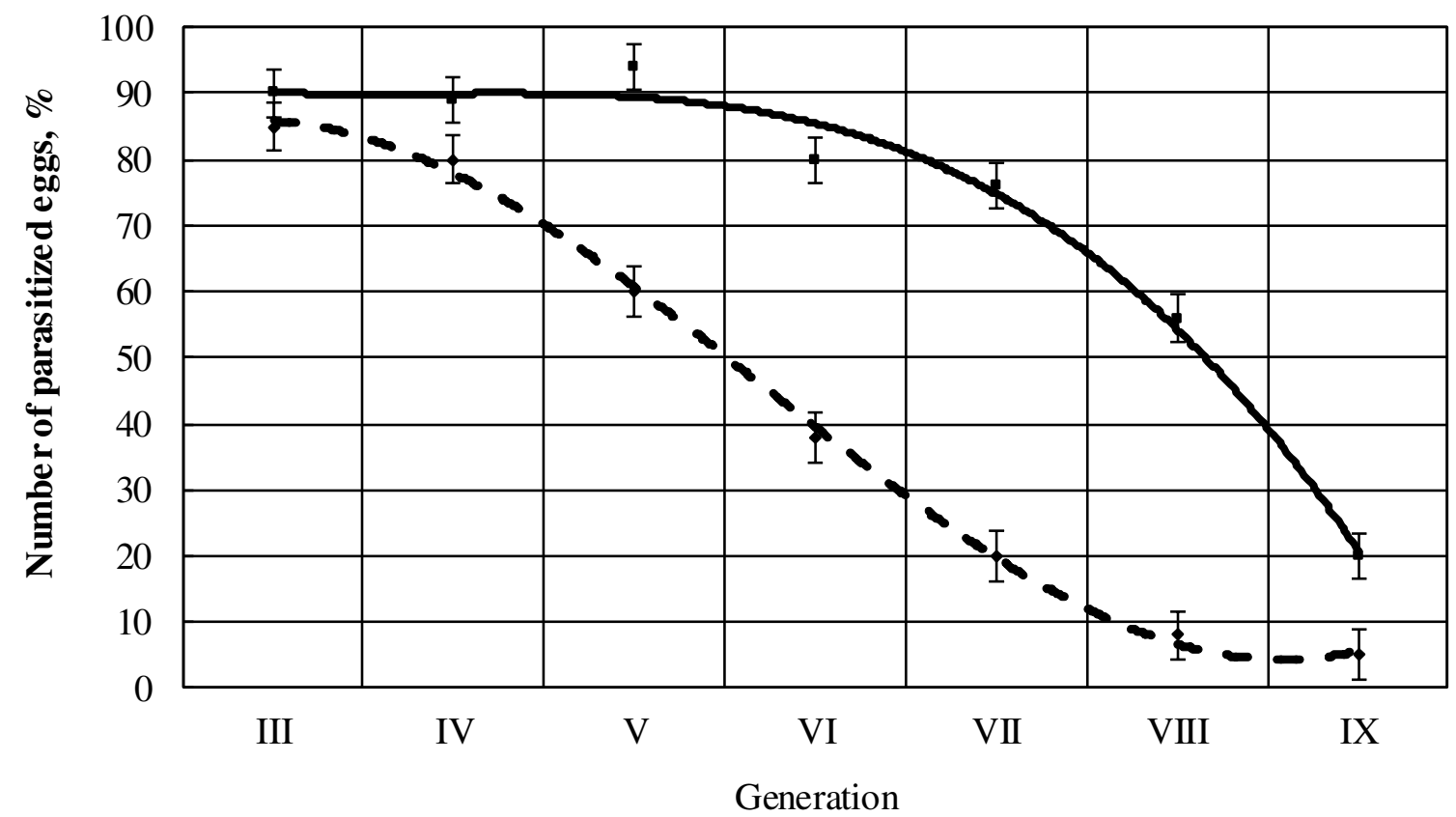

- Large eggs • Small eggs

Fig. 4. Influence of the size of grain moth eggs on the level of parasitized eggs by Trichogramma pintoi Voeg.

Comparison of the effect of the size of grain moth eggs on such an indicator as the level of parasitized eggs for Trichogramma pintoi Voeg. and Trichogramma evanescens Westw. showed that regardless of the type of Trichogramma, the size of eggs directly affects this indicator. Therefore, the calibration operation should be an integral part of the process of production of the mother and industrial culture of Trichogramma.

Breeding on large grain moth eggs, which was received during the calibration process, has allowed increasing the number of generations of Trichogramma with the corresponding qualitative indicators. It allows extending Trichogramma production and improving its efficiency in biological protection of plants.

\section{Conclusions}

1. Studies have shown that Trichogramma pintoi Voeg. with using of selected large grain moth eggs from the third to the seventh generation had a level of parasitized eggs, which ranged from 76 to $90 \%$. When the small grain moth eggs were used from the third container of a pneumatic calibrator, the high level of parasitized eggs of the grain moth was only from the third to the fourth generation, which was in the range of 80 to $85 \%$.

2. Trichogramma evanescens Westw., bred on large grain moth eggs from the second to the seventh generation, had parasitized eggs, ranging from 83 to 93\%. When cultivating Trichogramma evanescens Westw. on grain moth eggs that have been cleaned only without calibration, the high level of parasitized eggs in the range of 78 to $80 \%$ was only from the second to fourth generation. Since the fifth generation, Trichogramma evanescens Westw., the level of parasitized eggs of grain moth have been reduced and it led to a decreasing efficiency of the biological preparation Trichogramma.

Further studies in this area should be directed towards determining the effect of the size of grain moth eggs on other qualitative Trichogramma indicators, such as: the level of search ability, the level of regeneration of individuals, the relative number of females, the level of deformed individuals, the duration of females life and the fecundity of females. 


\section{References}

[1] Hamouz P., Hamouzova K., Novotna K. Effects of spring herbicide treatments on winter wheat growth and grain yield. Scientia agriculturae bohemica, 46 (1), 2015, pp. 1-6.

[2] Vlasicova E., Naglova Z. Differences in the financial management of conventional, organic, and biodynamic farms. Scientia agriculturae bohemica, 46 (3), 2015, pp.106-111.

[3] Manandhara R., Wright M.G. Enhancing biological control of corn earworm, Helicoverpa zea and thrips through habitat management and inundative release of Trichogramma pretiosum in corn cropping systems. Biological Control, 89, 2015, pp. 84-90.

[4] Davies A.P., Pufke U.S., Zalucki M.P. Spatio-temporal variation in Helicoverpa egg parasitism by Trichogramma in a tropical Bt-transgenic cotton landscape. Agricultural and Forest Entomology, 13, 2011, pp. 247-258.

[5] Parsaeyan E., Safavi S.A., Saber M. etc. Effects of emamectin benzoate and cypermethrin on the demography of Trichogramma brassicae Bezdenko. Crop Protection, 110, 2018, pp. 269-274.

[6] Thubru D.P., Firake D.M., Behere G.T. Assessing risks of pesticides targeting lepidopteran pests in cruciferous ecosystems to eggs parasitoid, Trichogramma brassicae (Bezdenko). Saudi Journal of Biological Sciences, 25, 2018, pp. 680-688.

[7] Waage J.K., Lane J.A. The Reproductive Strategy of a Parasitic Wasp: II. Sex Allocation and Local Mate Competition in Trichogramma evanescens. The Journal of Animal Ecology, 53(2), 1984, pp.417-426.

[8] Pallewatta P.K.T.N.S. Factors afecting progeny and sex allocation by the egg parasitoid Trichogramma evanescens Westwood. Thesis, 1986, London 420 p.

[9] Голышин Н.M. Методические указания по промышленному производству трихограммы на биофабриках. Всесоюзный научно - исследовательский институт биологических методов защиты растений (Methodical instructions for the industrial production of trichograms at biofactories. All-Union Scientific Research Institute of Biological Methods of Plant Protection). Moscow: Science, 1983, 76 p. (In Russian).

[10] Golub G., Marus O., Chuba V. Parameters of pneumatic calibrator of grain moth eggs for Trichogramma production. Scientia agriculturae bohemica, 50 (2), 2019, pp. 117-126.

[11]Шелестова В.С., Мельничук С.Д., Гончаренко О.I. etc. Показники якості трихограми. Методичні рекомендації до застосування трихограми проти шкідників сільськогосподарських культур (The qualitative indicators of Trichogramma. Methodical recommendations on the application of Trichogramma against pests of agricultural crops). Kiev: NAU Publishing Center, 2004, 59 p. (In Ukrainian). 